UDK 528.14

\title{
JONOSFEROS ITAKOS KOVARIACIJA ATLIKUS GPS MATAVIMUS
}

\author{
Jonas Skeivalas \\ Geodezijos ir kadastro katedra, Vilniaus Gedimino technikos universitetas, \\ Sauletekio al. 11, LT-10223 Vilnius-40, Lietuva, \\ el.paštas: Jonas.Skeivalas@ap.vtu.lt
}

Iteikta 20050830 , priimta 20051214

\begin{abstract}
Santrauka. Straipsnyje analizuojama jonosferos įtaka atliekant pseudoatstumų ir nešlio fazių matavimus. Kadangi jonosferos būkle nèra pastovi, o kinta laike ir priklauso nuo GPS palydovų signalų sklidimo geometrijos, tai atitinkamai nèra pastovios matavimo taško koordinačiu klaidos dèl jonosferos įtakos. Nustatytos koreliacijos tarp dviejų pseudoatstumų bei tarp dviejų nešlio fazių skirtumų, gautų priimant signalus iš to paties palydovo skirtingais laiko momentais arba iš skirtingų palydovų tais pačiais laiko momentais, koeficiento teorinès reikšmès. Parodyta, kad GPS matavimo rezultatų apdorojimo procedūrose turi būti atsižvelgiama ì matavimo rezultatų koreliaciją. Analizuojama jonosferos įtaka taško koordinačių, nustatytų vieno dažnio GPS imtuvais, klaidoms absoliučiojoje koordinačių sistemoje.
\end{abstract}

Prasminiai žodžiai: GPS, jonosfera, koreliacija, pseudoatstumai.

\section{Ivadas}

Matavimus atliekant GPS, dèl jonosferos itakos vyksta palydovo signalu delsa, tad iškraipomi pseudoatstumų ir nešlio fazių matavimų rezultatai. Šiai ttakai eliminuoti sudaromi tiesiniai modeliai, arba jonosferos itakos klaida nustatoma pagal transliuojamas atitinkamas jonosferos modelio parametru reikšmes [1-10]. Tiesinius matavimo rezultatų modelius imanoma sudaryti turint dviejų nešlio dažniu GPS imtuvus. Tačiau matavimo rezultatams, gautiems vieno dažnio GPS imtuvais apdoroti tektu sudaryti pakankamai sudètingus jonosferos parametrų kaitos modelius. Todèl vieno dažnio imtuvai atliekant tikslius matavimus paprastai nėra naudojami. Signalo sklidimo iš palydovo, esančio žemai virš horizonto, delsa gali būti didesnè daugiau nei tris kartus, palyginti su signalo sklidimo iš palydovo, esančio ties zenitu, delsa [9].

Straipsnyje analizuojamas matavimo rezultatu, gautu vieno dažnio GPS imtuvais, tikslumas, ivertinant jonosferos itakos klaidu pokyčius. Apskaičiuotos teorinès koreliacijos tarp pseudoatstumu bei tarp nešlio faziu skirtumų, nustatytų priimant signalus iš keleto palydovų tais pačiais laiko momentais arba naudojant vieno palydovo signalus skirtingais laiko momentais, koeficiento reikšmès. Siūloma GPS matavimo rezultatu apdorojimo procedūrose taikyti koreliacijos ịtakos ivertinimo algoritmus.

\section{Teorinès kovariacijos nustatymo prielaidos}

Taško koordinačių (Žemès paviršiuje arba erdvèje aplink ja) nustatymo GPS imtuvais klaidos labai priklauso nuo jonosferos itakos. Ši ịtaka pasireiškia virpesiu sklidimo grupine delsa jonosferoje $\delta t_{g r}^{j o n}$ ir išreiškiama formule [9]

$$
\delta t_{g r}^{j o n}=\frac{40,3}{c f^{2}} T E C(t)
$$

čia $c$ - virpesių greitis vakuume, $f-L 1$ arba $L 2$ kanalo nešlio dažnis, TEC (Total Electronic Content) - laisvuju elektronų skaičius jonosferos sluoksnio stulpe, kurio pagrindo plotas lygus $1 \mathrm{~m}^{2}$. Šis skaičius priklauso nuo jonosferos tam tikru metu būklès.

Apytikslę jonosferos itakos pataisą, matuojant vieno dažnio imtuvais, galima nustatyti panaudojant iš palydovo transliuojamas jonosferos modelio parametru reikšmes. Taikant tokius modelius jonosferos poveiki galima sumažinti apie $70 \%$ [10].

Išmatuoto pseudoatstumo $R_{i}^{k}\left(t_{i}\right)$ tarp $i$-ojo imtuvo ir $k$-ojo palydovo epochoje $t_{i}$ klaida dèl jonosferos itakos yra

$$
\delta R_{i}^{k, j o n}\left(t_{i}\right)=c \cdot \delta t_{g r}^{j o n}=\frac{40,3}{f^{2}} T E C\left(t_{i}\right) .
$$

Nešlio virpesių fazès $\Phi_{i}^{k}(t)$ klaida dèl jonosferos poveikio faziniais ciklais:

$$
\delta \Phi_{i}^{k, j o n}\left(t_{i}\right)=f \cdot \delta t_{g r}^{j o n}=\frac{40,3}{c f} T E C\left(t_{i}\right) .
$$

GPS matavimų rezultatai (pseudoatstumai ir nešlio fazès) dèl jonosferos poveikio koreliuoja. Todèl apdorojant matavimų rezultatus tenka atsižvelgti i jų koreliacija. 
Nustatysime teorines jonosferos lemiamas koreliacijos koeficiento reikšmes.

Kovariacija tarp dviejų pseudoatstumų, nustatytu skirtingose epochose $t_{i}$ ir $t_{j}$, priimant signalus iš to paties palydovo $k$ (galima skaičiuoti toje pačioje epochoje iš skirtingu palydovu), užrašoma taip:

$$
\begin{aligned}
& K\left\{R_{i}^{k}\left(t_{i}\right), R_{i}^{k}\left(t_{j}\right)\right\}=M\left\{\left[R_{i}^{k}\left(t_{i}\right)-M R_{i}^{k}\left(t_{i}\right)\right] \times\right. \\
& \left.\left[R_{i}^{k}\left(t_{j}\right)-M R_{i}^{k}\left(t_{j}\right)\right]\right\}=M\left\{\delta R_{i}^{k}\left(t_{i}\right) \cdot \delta R_{i}^{k}\left(t_{j}\right)\right\},
\end{aligned}
$$

čia $\operatorname{MR}_{i}^{k}\left(t_{i}\right)$ - pseudoatstumo $R_{i}^{k}\left(t_{i}\right)$ vidurkis (matematinè viltis), $\delta R_{i}^{k}\left(t_{i}\right)$ - pseudoatstumo atsitiktine klaida, atsirandanti dèl atsitiktinių faktorių.

Pseudoatstumo atsitiktinę klaidą $\delta R_{i}^{k}\left(t_{i}\right)$ galima užrašyti dviejų komponenčių suma:

$$
\delta R_{i}^{k}\left(t_{i}\right)=\delta R_{i, m}^{k}\left(t_{i}\right)+\delta R_{i, a}^{k, j o n}\left(t_{i}\right)
$$

čia $\delta R_{i, m}^{k}\left(t_{i}\right)$ - pseudoatstumo atsitiktinè klaida dèl matavimo procedūrų netobulumo ir kitų atsitiktinių faktoriu, $\delta R_{i, a}^{k, j o n}\left(t_{i}\right)$ - pseudoatstumo atsitiktinè klaida dèl jonosferos itakos.

Taigi kovariaciją (4), atsižvelgiant i išraišką (5), galima ivertinti tokia formule:

$$
\begin{aligned}
& K\left\{R_{i}^{k}\left(t_{i}\right), R_{i}^{k}\left(t_{j}\right)\right\}=M\left\{\delta R_{i, m}^{k}\left(t_{i}\right) \cdot \delta R_{i, m}^{k}\left(t_{j}\right)\right\}+ \\
& M\left\{\delta R_{i, a}^{k, j o n}\left(t_{i}\right) \cdot \delta R_{i, a}^{k, j o n}\left(t_{j}\right)\right\}=K\left\{\delta R_{i, m}^{k}\left(t_{i}\right), \delta R_{i, m}^{k}\left(t_{j}\right)\right\}+ \\
& K\left\{\delta R_{i, a}^{k, j o n}\left(t_{i}\right), \delta R_{i, a}^{k, j o n}\left(t_{j}\right)\right\},
\end{aligned}
$$

čia atsitiktinès klaidos $\delta R_{i, m}^{k}\left(t_{i}\right) \quad$ ir $\quad \delta R_{i, a}^{k, j o n}\left(t_{j}\right)$ nekoreliuoja.

Nagrinèsime formulès (6) antrają komponentę, t. y. jonosferos itakos atsitiktinių klaidų kovariaciją. Taikydami formulę (2) galime parašyti

$$
\begin{aligned}
& K\left\{\delta R_{i, a}^{k, j o n}\left(t_{i}\right), \delta R_{i, a}^{k, j o n}\left(t_{j}\right)\right\}=\frac{40,3^{2}}{f^{4}} \times \\
& K\left\{\operatorname{TEC}\left(t_{i}\right), \operatorname{TEC}\left(t_{j}\right)\right\} .
\end{aligned}
$$

Kovariaciją $K\left\{\operatorname{TEC}\left(t_{i}\right), T E C\left(t_{j}\right)\right\}$ galima išreikšti taip:

$$
\begin{aligned}
& K\left\{\operatorname{TEC}\left(t_{i}\right), \operatorname{TEC}\left(t_{j}\right)\right\}=M\left\{\delta \operatorname{TEC}\left(t_{i}\right) \times\right. \\
& \left.\left[\delta \operatorname{TEC}\left(t_{i}\right)+\Delta \delta \operatorname{TEC}\left(t_{i j}\right)\right]\right\}= \\
& =M\left\{\delta \operatorname{TEC}\left(t_{i}\right)\right\}^{2}=\sigma_{T E C\left(t_{i}\right)}^{2},
\end{aligned}
$$

čia

$$
\begin{aligned}
& \delta \operatorname{TEC}\left(t_{i}\right)=\operatorname{TEC}\left(t_{i}\right)-\operatorname{MTEC}\left(t_{i}\right), \\
& \delta \operatorname{TEC}\left(t_{j}\right)=\delta \operatorname{TEC}\left(t_{i}\right)+\Delta \delta \operatorname{TEC}\left(t_{i j}\right), \\
& \Delta \delta \operatorname{TEC}\left(t_{i j}\right)-\operatorname{TEC}\left(t_{i}\right)-\text { atsitiktiniu klaidu pokytis }
\end{aligned}
$$

laiko intervale $t_{i j}$,

$\sigma_{T E C\left(t_{i}\right)}$ - standartinis nuokrypis,

$M\left\{\delta \operatorname{TEC}\left(t_{i}\right) \cdot \Delta \delta \operatorname{TEC}\left(t_{i j}\right)\right\}=0, \quad$ nes atsitiktiniai dydžiai skliaustuose yra nepriklausomi.

$\Delta \delta T E C\left(t_{i j}\right)$ pokytis nepriklauso nuo $\delta T E C\left(t_{i}\right)$ būsenos $t_{i}$ epochoje.

Standartiniam nuokrypiui $\sigma_{T E C}\left(t_{j}\right)$ skaičiuoti galima taikyti formulę

$$
\sigma_{T E C\left(t_{j}\right)}^{2}=\sigma_{T E C\left(t_{i}\right)}^{2}+\sigma_{\Delta \delta T E C\left(t_{i j}\right)}^{2}=2 \sigma_{T E C\left(t_{i}\right)}^{2} .
$$

Pokyčio $\Delta \delta T E C\left(t_{i j}\right)$ standartini nuokrypi $\sigma_{\Delta \delta T E C}\left(t_{j j}\right)$ galima laikyti lygų $\sigma_{T E C\left(t_{i}\right)}$.

Išmatuoto pseudoatstumo $R_{i}^{k}\left(t_{i}\right)$ klaidos dèl jonosferos įtakos standartinis nuokrypis, taikant formulę (2) -

$$
\sigma\left\{\delta R_{i, a}^{k, j o n}\left(t_{i}\right)\right\}=\frac{40,3}{f^{2}} \sigma_{T E C\left(t_{i}\right)}
$$

Koreliacijos tarp $\delta R_{i, a}^{k, j o n}\left(t_{i}\right) \quad$ ir $\quad \delta R_{i, a}^{k, j o n}\left(t_{j}\right)$ koeficientas, taikant formules (7-10), skaičiuojamas pagal formulę:

$$
r\left\{\delta R_{i, a}^{k, j o n}\left(t_{i}\right), \delta R_{i, a}^{k, \text { jon }}\left(t_{j}\right)\right\}=\frac{K\left\{\delta R_{i, a}^{k, \text { jon }}\left(t_{i}\right), \delta R_{i, a}^{k, j o n}\left(t_{j}\right)\right\}}{\sigma\left\{\delta R_{i, a}^{k, j o n}\left(t_{i}\right)\right\} \sigma\left\{\delta R_{i, a}^{k, j o n}\left(t_{j}\right)\right\}}=
$$

$$
\frac{40,3^{2} / f^{4} \sigma_{T E C\left(t_{i}\right)}^{2}}{40,3 / f^{2} \sigma_{T E C\left(t_{i}\right)} \cdot 40,3 / f^{2} \sigma_{T E C\left(t_{j}\right)}}=0,71 \text {. }
$$

Analogiškai skaičiuodami nustatome koreliacijos tarp nešlio fazès atsitiktinių klaidų $\delta \Phi_{i, a}^{k, j o n}\left(t_{i}\right)$ ir $\delta \Phi_{i, a}^{k, j o n}\left(t_{j}\right)$ dèl jonosferos poveikio koeficientą:

$$
r\left\{\delta \Phi_{i, a}^{k, j o n}\left(t_{i}\right), \delta \Phi_{i, a}^{k, j o n}\left(t_{j}\right)\right\}=0,71
$$

Ši skaičiavimų eiga rodo, kad pseudoatstumų ir nešlio fazių matavimo rezultatu apdorojimo procedūrose turètų būti atsižvelgiama i koreliaciją. Matavimo rezultatu koreliacijos tarp skirtingų epochų dèl jonosferos itakos koeficientų matricos:

$\boldsymbol{R}=\left(\begin{array}{cccc}r_{11} & r_{12} & \ldots & r_{1 n} \\ r_{21} & r_{22} & \ldots & r_{2 n} \\ \ldots & \ldots & \ldots & \ldots \\ r_{n 1} & r_{n 2} & \ldots & r_{n n}\end{array}\right)=\left(\begin{array}{cccc}1,0 & 0,71 & \ldots & 0,71 \\ 0,71 & 1,0 & \ldots & 0,71 \\ \ldots & \ldots & \ldots & \ldots \\ 0,71 & 0,71 & \ldots & 1,0\end{array}\right)$ 
čia $r_{i j}-i$-osios ir $j$-osios epochų matavimo rezultatu koreliacijos koeficientai.

\section{Imtuvo koordinačių pokyčiai dėl jonosferos}

Pagal tyrimų rezultatus [5-7] jonosferos elektronų skaičius ties fiksuotu Žemès paviršiaus tašku pagal Saulès aktyvumą per vieną valandą gali pakisti nuo keleto dešimtujų TECU dalių iki keleto dešimčių TECU (Total Electronic Content Unit). TECU yra TEC mato vienetas, lygus $10^{16}$ elektronu $/ \mathrm{m}^{2}$. 1 TECU sukelia elektromagnetinių virpesių sklidimo jonosferoje delsą, lygią 0,351 ns. Taigi dèl 1 TECU sukeltos signalo delsos atsiranda pseudoatstumo klaida, kuri lygi

$$
\delta R^{j o n}=c \cdot \delta t=3 \cdot 10^{8} \cdot 0,351 \cdot 10^{-9}=0,1 \mathrm{~m} .
$$

Matavimų rezultatuose per valandą išmatuoto pseudoatstumo klaida dèl jonosferos įtakos gali kisti nuo keleto centimetrų iki keleto metrų. Pseudoatstumo klaida $\delta R^{j o n}$ lemia nustatomo taško koordinačių klaidas $\delta X_{i}, \delta Y_{i}, \delta Z_{i}$. Galima parašyti:

$$
\begin{aligned}
& \delta R^{j o n}=\sqrt{\left(\delta X^{k}+\delta X_{i}\right)^{2}+\left(\delta Y^{k}+\delta Y_{i}\right)^{2}+\left(\delta Z^{k}+\delta Z_{i}\right)^{2}}= \\
& \sqrt{\delta X_{i}^{2}+\delta Y_{i}^{2}+\delta Z_{i}^{2}}
\end{aligned}
$$

čia palydovo koordinačių klaidos $\delta X^{k}, \delta Y^{k}, \delta Z^{k}$ dèl jonosferos itakos yra lygios nuliui.

Nagrinedami atsitiktines klaidų komponentes gauname šias standartinių nuokrypių išraiškas:

$$
\sigma_{\delta R^{j o n}}^{2}=\frac{\delta X_{i}^{2}}{\delta R^{2}} \sigma_{\delta X}^{2}+\frac{\delta Y_{i}^{2}}{\delta R^{2}} \sigma_{\delta Y}^{2}+\frac{\delta Z_{i}^{2}}{\delta R^{2}} \sigma_{\delta Z}^{2}
$$

Laikydami, $\operatorname{kad} \sigma_{\delta X} \approx \sigma_{\delta Y} \approx \sigma_{\delta Z}=\sigma_{0}$, rašome:

$$
\sigma_{\delta R^{j o n}}^{2}=3 \sigma_{0}^{2}, \text { arba } \sigma_{0}=0,6 \sigma_{\delta R^{j o n}} .
$$

Todèl, esant pseudoatstumo $1 \mathrm{~m}$ standartiniam nuokrypiui dèl jonosferos ịtakos, taško koordinatès igauna vidutinius $0,6 \mathrm{~m}$ standartinius nuokrypius, t. $\mathrm{y}$. $\sigma_{\delta X} \approx \sigma_{\delta Y} \approx \sigma_{\delta Z}=0,6 \mathrm{~m}$.

Taikant vieno dažnio GPS imtuvus to paties taško koordinačių pokyčiai per valandą dèl jonosferos įtakos gali svyruoti nuo keleto centimetrų iki keleto metrų. Tai priklauso nuo jonosferos būklès, o ši - nuo Saulès aktyvumo.

\section{Išvados}

1. Pseudoatstumų ir nešlio fazių matavimo rezultatai dèl jonosferos įtakos koreliuoja, todèl apdorojant juos turi būti taikoma jų kovariacijų matrica.
2. Atliekant matavimus vieno dažnio GPS imtuvais, to paties taško koordinačiu pokyčiai per valandą gali kisti nuo keleto centimetrų iki keleto metrų.

\section{Literatūra}

1. Baran, L. W.; Ephishov, I. I. and Shagimuratov, I. I. Ionospheric Total Electron Content Behavior During November 1997 Storm. Phys. Chem. Earth (C), 26, 2001, p. 341-346.

2. Cander, L. R.; Mihajlovic, S. J. Forecasting ionospheric structure during the great geomagnetic storm. J. Geophys. Res., Vol 103, A1, 1998, p. 391-398.

3. Hajj, G. A.; Lee, L.; C; Pi, X.; Romans, L. J.; Schreiner, W. S.; Straus, P. R. and Wang, C. COSMIC GPS ionospheric sensing and space weather. Terr. Atmos. Oceanic Sci., 11, 2000, p. 235-272.

4. Ho, C. M.; Manucci, A. J.; Linqwister, U. et al. Global ionospheric TEC variations during January 101997 storm. Geophys. Res. Letts, 25, 1998, p. 2589-2592.

5. Jakowski, N.; Schluter, S.; Sardon, E. Total electron content of the ionosphere during the geomagnetic storm on 10 January 1997. J. Atmos. Terr. Physics, 61, 1999, p. 299307.

6. Mannucci, A. J.; Wilson, B.; Yuan, D.; Linqwister, U. and Runge, T. A global mapping technique for GPS-derived ionospheric total electron content measurements. Radio Science, Vol 33, 1998, p. 565-582.

7. Pottiaux, E.; Warnant, R. Quality Assessment of GPS Integrated Precipitable Water Vapor Estimations using Water Vapor Radiometer Observations. GPS Solutions, Vol 6, No 1-2, 2002, p. 11-17.

8. Skeivalas, J. Construction of linear models of pseudoranges and carier phases for eliminating the ionosphere influence. Geodesy and Cartography (Geodezija ir kartografija), Vol XXIX, No 3. Vilnius: Technika, 2003, p. 61-64 (in Lithuanian).

9. Būga, A. Ionospheric influence on delay of GPS satellites signals. Geodesy and Cartography (Geodezija ir kartografija), Vol XXV, No 4. Vilnius: Technika, 1999, p. $150-155$ (in Lithuanian).

10. Skeivalas, J.; Būga, A. Ionospheric influence on GPS observations. In: The $6^{\text {th }}$ International Conference „Environmental Engineering“, Vol 2, May 26-27, 2005. Vilnius, p. 1005-1007.

\section{Jonas SKEIVALAS. Prof, Doctor Habil.}

Vilnius Gediminas Technical University. Dept of Geodesy and Cadastre, Saulètekio al. 11, LT-10223 Vilnius-40, Lithuania $(\mathrm{Ph}+3705$ 2744703, Fax +370 5 2744705),

e-mail: jonas.skeivalas@ap.vtu.lt.

Author of two monographs and more than 130 scientific papers. Participated in many intern conferences and research visits to the Finish Geodetic Institute.

Research interests: processing of measurements with respect to tolerances, adjustment of geodetic networks. 